\title{
Erratum to: Small colorectal cystic metastases to the liver: still a diagnostic dilemma? A report of a case and a review of the literature
}

\author{
Davide Papis • Matteo Barabino - Giuseppe Petralia • \\ Alessandro Cadeo $\cdot$ Enrico Opocher
}

Published online: 24 November 2011

(C) Springer-Verlag 2011

\section{Erratum to: Updates Surg}

DOI 10.1007/s13304-011-0115-2

The original publication of the article does not indicate the second affiliation of the corresponding author. This is now considered as the first affiliation for the original publication.

Details of affiliation

D. Papis - M. Barabino - A. Cadeo - E. Opocher Hepatobilyopancreatic and Digestive Surgery Division S. Paolo Hospital, University of Milan, Via A. Di Rudini', 8-20142 Milan, Italy

The online version of the original article can be found under doi:10.1007/s13304-011-0115-2.

D. Papis · M. Barabino - A. Cadeo · E. Opocher Hepatobilyopancreatic and Digestive Surgery Division, S. Paolo Hospital, University of Milan, Via A. Di Rudini', 8-20142 Milan, Italy

e-mail: matteo.barabino@alice.it

A. Cadeo

e-mail: alecadeo@yahoo.it

E. Opocher

e-mail: enrico.opocher@unimi.it

D. Papis $(\bowtie)$

General and Laparoscopic Surgery Division, European Institute of Oncology, University of Milan, Via Ripamonti 435,

20141 Milan, Italy

e-mail: davide.papis@gmail.com

\section{G. Petralia}

Radiology Division, European Institute of Oncology, University of Milan, Via Ripamonti 435, 20141 Milan, Italy

e-mail: giuseppe.petralia@ieo.it 